\title{
Diagnosis of brucellosis in sheep and goats raw milk by fast and reliable techniques
}

\author{
D.A. Almashhadany \\ Department of Medical Laboratory Sciences, College of Science, Knowledge University, Erbil, Iraq
}

\begin{tabular}{l} 
Article information \\
\hline Article history: \\
Received August 26, 2020 \\
Accepted January 21, 2021 \\
Available online October 1, 2021 \\
\hline Keywords: \\
Brucella \\
MRT \\
ELISA \\
Iraq \\
\end{tabular}

Correspondence:

S.S. Al-Mahmood

dhary.hammed@knu.edu.iq

\begin{abstract}
This study aimed to evaluate the occurrence of brucellosis in sheep and goats' raw milk samples by detecting anti-Brucella antibodies and Brucella species at Erbil governorate. A total of 320 raw milk samples (150 sheep milk and 170 goats milk) were irregularly collected from dairy females. The overall occurrence of Brucella antibodies in samples of sheep and goats raw milk was $11.6 \%$ and $9.7 \%$ according to MRT and indirect ELISA, respectively. Isolation of Brucella (B.) species from samples of raw milk was $7.8 \%$. The isolated species of Brucella were B. melitensis and B. abortus. A noticeable increase in frequency during September to November was observed. In conclusion, brucellosis is still a considerable public health threat in the Erbil. Based on the tests performance, the study recommends MRT in standard observing of brucellosis in milk aggregate farms, centers, and dairy manufactories. Customers are also recommended to adequately pasteurize the milk in order to damage this milk-borne pathogen before ingestion or saleable handling.
\end{abstract}

DOI: 10.33899/ijvs.2021.127697.1523, (CAuthors, 2021, College of Veterinary Medicine, University of Mosul.

This is an open access article under the CC BY 4.0 license (http://creativecommons.org/licenses/by/4.0/).

\section{Introduction}

Brucellosis is a severely weakening and deactivating classical bacterial zoonotic disease, it signifies a high public health threat and poses a major threat to human health. It is a very old zoonotic disease since animals are the only source of infection, and a recent indication from Egyptian ancient skeletons has revealed that brucellosis has been existing for no less than 750 BC. Brucella species can be traced back to 2.8 million years by probable indication of pathologic variations in a late Pliocene hominin skeleton. Furthermore, molecular tests demonstrated the continuance of $B$. melitensis DNA in a 700-year-old skeleton from medieval Italy, and confirming the permanence of this zoonotic contagion, and even a specific lineage, in the Mediterranean area over the centuries $(1,2)$. According to the WHO, the FAO, and the Office International des Epizooties (OIE), brucellosis is yet one of the most significant and prevalent zoonoses globally, but also ranks as one of the seven record neglected diseases (NDs) according to the World Health
Organization, due to its non-descript clinical presentation in human inhabitants. Brucellosis has been eradicated in many developed countries, but it is still prevalent in various regions, particularly in the Mediterranean Basin, Africa, the Middle East (including Iraq), the Arabian Gulf, the Indian subcontinent, and some developed countries with a low income, limited resources, and frequent contact with livestock animals. There are approximately 500.000 new cases of human brucellosis are reported yearly around the world, with around 10 per 100,000 populations. However, many researchers declared that this figure underestimates the realistic epidemiology and the actual occurrence is assessed to be $5,000,000$ to $12,500,000$ cases per annum (3). This disease is caused by the Gram-negative bacterial genus Brucella. Food sources of infection are typically the unpasteurized milk and dairy products, undercooked meat, animal bone marrow, and probably undercooked seafood. Human brucellosis is acquired essentially through direct touch of damaged skin or mucous membrane with infected animal tissues, consumption of infected meat or 
unpasteurized dairy products, and inhalation of infectious aerosols. Although the Human-to-human transmission is still under debate, it has been described to occur through vertical and sexual routes. The transmission may also take place through blood transfusions or tissue transplantation, and exposure to contaminated material during helping at birth. Breastfeeding mothers infected with Brucella may pass the infection on to their babies (4). At the time, at least 12 Brucella species are documented under Brucella genus; $B$. abortus, B. melitensis, B. ovis, B. canis, B. suis, B. neotomae, B. ceti, B. pinnipedialis, B. microti, B. Papionis, B. inopinata, and $B$. vulpis. Species are differentiated by the production of urease and $\mathrm{H}_{2} \mathrm{~S}$, dye sensitivity, cell wall antigens, and phage sensitivity. The major species are divided into multiple biovars. Brucella species are facultative intracellular, gram-negative coccobacilli (short rods) measuring about 0.6 to $1.5 \mu \mathrm{m}$ by $0.5-0.7 \mu \mathrm{m}$, nonspore-forming, lack capsules or flagella, therefore, are nonmotile (5). Growth Brucella species in vitro are slow and primary isolation may require up to 4 weeks of incubation at $37^{\circ} \mathrm{C}$. They are aerobic, but some strains require $5-10 \% \mathrm{CO}_{2}$ for primary isolation. A handful of culture media was devised for the cultivation of Brucella such as Brucella agar, albumin agar, and trypticase soy agar that may be enriched by the addition of blood or serum. Also, there are four unnamed isolates without reported infections, Brucella NFXXXX Australian rat (6), $B$. unnamed Blue dotted ray; $B$. inopinata-like 09RB8471 African bullfrogs and Big-eyed tree frog, and Brucella UK8/14 White's tree frog. Brucella species can grow and survive for protracted periods in the environment, it remains viable outside animal hosts for the duration ranging from less than a day to $>8$ months, depending on environmental factors such as temperature, humidity, exposure to sunlight, and the presence of organic matter. Indeed, survival is longer (months to years) when the temperature is low. In circumstances of low temperatures, high humidity, and no sunlight, Brucella species may remain viable for several months in aborted fetuses, manure, water, wool, hay, and other materials. They also can withstand drying, especially when organic material is present, and can survive in soil and dust. Their persistence in unpasteurized cheese is influenced by factors such as the temperature, water content, and type of fermentation, $\mathrm{pH}$, and ripening time. Survival times of years have been reported in frozen meat (7).

Brucella species have a wide range of domestic, wild animals, and marine hosts, including cattle, buffaloes, camels, sheep, goats, pigs, reindeer, seals, cetaceans, and voles. In sheep and goats, brucellosis is mainly caused by $B$. melitensis, which contains three biovars; 1,2 , and 3 . The distribution of $B$. melitensis has long been associated with the Mediterranean littoral regions, however, it is now known to be much more widely distributed with South- East Asia, North America, and North Europe (8).

Brucella infection is one of the major bacterial agents that cause tremendous economic losses due to abortion in sheep and goat flocks in many countries. In the livestock industry, the disease is manifested by abortions during the last third of pregnancy, stillbirths, weak lambs and kids, infertility and characterized essentially by epididymitis and orchitis in males, placentitis in pregnant female animals, with excretion of the organisms in milk and uterine discharges in female animals. It also causes a significant loss of productivity through high morbidity. Sheep and goats' brucellosis is prevalent globally, however, it is remains a serious threat among low- and middle-income countries (9).

Usually, it is difficult to diagnose Brucella because of the long incubation period, which ranges from 5 days to 5 months. The diseases can progress in different forms, acute, chronic, or asymptomatic, also the brucellosis has to be obligatorily confirmed by laboratory testing. The choice of diagnostic tools depends on the objectives of the study and on the general epidemiological situation of the disease in the region. Overall, rapid serological tests employing serum, milk, meat juice are the most straightforward and affordable, while bacteriological isolation and identification of Brucella is an exhausting process that might require weeks (10).

The epidemiology of Brucella among the food of animal origin at Erbil Governorate is not well established so far, therefore, the objectives of this study were to study the occurrence of brucellosis in Erbil governorate by detecting anti-Brucella antibodies and Brucella species in raw milk samples from sheep and goat by using MRT and indirect ELISA. The sensitivity and specificity of MRT and ELISA were evaluated according to standard equations; where the brucellosis isolation method was adopted as the gold standard. Also, the seasonal variations of brucellosis were addressed.

\section{Materials and methods}

\section{Samples collection and transport}

Throughout the interval from July to December 2019, a total of 320 raw milk samples from sheep and goats were obtained (150 from sheep and 170 samples from goats). Each sample (about $200 \mathrm{ml}$ ) was randomly collected aseptically into labeled sterile plastic containers from retail milk shops in different markets in Erbil Governorate. Under cool conditions, samples were transported directly to the Department of Medical Lab Science (DMLS) at Knowledge University (KNU). The samples were stored in deep freezer at $-18^{\circ} \mathrm{C}$ and were evaluated within $48-72$ hours of the collection (11).

\section{Milk Ring Test (MRT)}

Anti-Brucella antibodies were detected in raw milk samples by the milk ring test (MRT) antigen (JOVAC, Jordan), according to manufacturer's instructions. Briefly, one drop ( $\sim 0.05 \mathrm{ml})$ of MRT reagent was added to $1 \mathrm{ml}$ of whole milk in a narrow test tube $(11 \mathrm{x} 100 \mathrm{~mm})$ and incubated at $37^{\circ} \mathrm{C}$ for $1-3$ hours. In the absence of antibodies to anti-Brucella, the mixture remains homogeneously bluish 
white through the tube. The presence of Anti-Brucella antibodies is inferred by a white mixture with a blue ring on the top (10).

\section{Indirect ELISA test}

The indirect ELISA tests were performed according to the manufacturer's protocol (ID Screen ${ }^{\circledR}$ Brucellosis, ID Vet Innovative Diagnostics, France). Briefly, all reagents were allowed to come to room temperature $\left(21^{\circ} \mathrm{C} \pm 5^{\circ} \mathrm{C}\right)$ before use and homogenized by inversion or vortex. Milk sample was allowed to still so that the cream separates from the lactoserum (cream on the top, lactoserum on the bottom). Lactoserum containing the antibodies was drawn carefully to a separated sterile clean tube for indirect ELISA reaction (12).

\section{Isolation and identification of Brucella}

The Brucella species were isolated from raw milk samples was done under sterilized conditions, according to the standard methods adopted in this field. Inoculated plates (Brucella broth and Brucella agar, HiMedia, India) were incubated aerobically, as well as in the existence of 5\%-10\% carbon dioxide at $37^{\circ} \mathrm{C}$. The incubated plates were examined for up to 7 seven days. The questionable colonies were subjected to biochemical tests for identification purposes $(10,12)$.

\section{Diagnostic performance of MRT and indirect ELISA}

The sensitivity and specificity of MRT and indirect ELISA were evaluated according to standard equations; where the brucellosis isolation method was adopted as the gold standard.

\section{Statistical analysis}

Data were analyzed using SPSS software version 25, confidence intervals were assessed using normal distribution approximation at an alpha level of 0.05. Chi-square test was applied to test of the difference between groups.

\section{Results}

\section{Seroprevalence of Brucella}

The overall occurrence of Brucella antibodies in raw milk samples was $11.6 \%$ according to MRT (Table 1).

The results showed that the percentage of positive samples among goat's milk was insignificantly higher than that found in sheep milk samples. It is assessed that up to $15.6 \%(95 \% \mathrm{CI})$ of the sheep and goats raw milk would be seropositive for Brucella in Erbil Governorate if screened by MRT assay (Table 1). On contrary, ELISA assay found $9.7 \%$ of samples to contain anti-Brucella antibodies (Table 1).

Similarly, insignificant increase in frequency among goats was also noted in ELISA assay. According to indirect ELISA, $6.68 \%$ - $13.47 \%$ (95\% CI) of sheep and goats in Erbil are expected to be seropositive for brucellosis by ELISA. There are no significant differences neither between the two serotests $(p=0.436)$ in terms of brucellosis detection, nor between the populations screened (Table 1).

Table 1: Seroprevalence of Brucella among sheep and goats raw milk

\begin{tabular}{lcccc}
\hline Milk type & No. Examined & Positive samples No (\%) & $95 \%$ CI & $P$ value $^{*}$ \\
\hline MRT & & & & \\
Sheep milk & 150 & $16(10.7)$ & $6.22-16.74$ & 0.054 \\
Goat milk & 170 & $21(12.4)$ & $7.81-18.26$ & \\
\hline Total & 320 & $37(11.6)$ & $8.27-15.58$ & \\
\hline ELISA & & & & \\
Sheep milk & 150 & $13(8.7)$ & $4.70-14.36$ & 0.054 \\
Goat milk & 170 & $18(10.6)$ & $6.40-16.22$ & \\
\hline Total & 320 & $31(9.7)$ & &
\end{tabular}

${ }^{*} P$ value less than 0.05 is considered significant.

\section{Prevalence of Brucella species}

The results indicated that the overall isolation rate of Brucella species from raw milk samples of sheep and goats was $7.8 \%$. It is distinctly clear that finding rate in goat milk was higher than sheep milk samples. Successful bacteriological isolation of Brucella spp. indicates active brucellosis. The identified species of Brucella were $B r$. melitensis and $\mathrm{Br}$. abortus without any significant difference in distribution in sheep or goats' milk samples (Table 2).

\section{Diagnostic performance of MRT and ELISA}

The Milk Ring Test technique(MRT) detected more cases of brucellosis $11.6 \%$ than the classical culture procedure $7.8 \%$ in both sheep and goat milk. Sensitivity, specificity, positive predictive value (PPV), and negative predictive value (NPV) of MRT are given in table 3. The accuracy (efficiency) of MRT in detecting ovine and caprine brucellosis is $94.1 \%$ in comparison to the culture method. In addition to its accuracy, the high specificity of MRT test candidates it to be a simple alternative screening/diagnostic method for ruling out Brucella infection rather than confirming the infection in suspected animal/herd. 
Table 2: Isolation of Brucella species from sheep and goat raw milk

\begin{tabular}{lcccc}
\hline Milk type & Br. abortus No. (\%) & Br. melitensis No. (\%) & Total No. $(\%)$ & $P$ value \\
\hline Sheep milk & $4(36.4)$ & $7(63.6)$ & $11(7.3)$ & \multirow{2}{*}{0.935} \\
Goat milk & $5(35.7)$ & $9(64.3)$ & $14(8.2)$ & \\
\hline Total & $9(36.0)$ & $16(64.0)$ & $25(7.8)$ & \\
\hline
\end{tabular}

Table 3: The performance of the serological tests for detection of brucellosis in sheep and goats

\begin{tabular}{lcc}
\hline & MRT $(95 \%$ CI) & ELISA (95\% CI) \\
\hline Sensitivity & $73.33(44.90-92.21)$ & $84.62(54.55-98.08)$ \\
Specificity & $95.86(91.21-98.47)$ & $97.89(93.95-99.56)$ \\
PPV & $59.99(39.27-77.66)$ & $77.21(51.92-91.40)$ \\
NPV & $97.70(94.83-98.99)$ & $98.69(95.46-99.63)$ \\
Accuracy & $94.10(89.25-97.21)$ & $96.85(92.74-98.99)$ \\
\hline
\end{tabular}

PPV: Positive Predictive Value, NPV: Negative Predictive Value.

\section{Temporal Dispersal of seropositive samples}

Differences in the Brucella antibodies prevalence among the sheep and goat raw milk samples during six months were also investigated (Figure 1). In spite of the noticeable increase in frequency during autumn (September to November), no relationship between study period and brucellosis distribution was found statistically. However, autumn progress was related with declining in brucellosis $\left(\mathrm{r}^{2}\right.$ $=0.867)$.

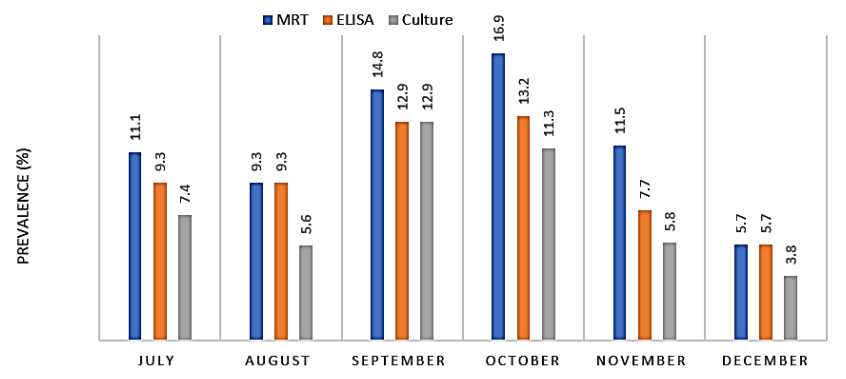

Figure 1: Distribution of raw milk positive samples for brucellosis during study period.

\section{Discussion}

Clinical human and animal brucellosis takes overabundance of synonyms like Malta fever, undulant fever, Mediterranean fever, Rock of Gibraltar fever, Neapolitan fever, Crimean fever, Corps disease, contagious abortion, and Bang's disease, and most of these names are still used in different regions of the world. It is one of the most significant zoonotic foodborne diseases in the world, brucellosis, is still present in Iraq, and is causing much distress to the country $(2,10,13)$. This study addresses fast and reliable techniques for screening of Brucella antibodies among sheep and goats raw milk in Erbil Governorate.
On one hand, the general occurrence of Brucella antibodies in the raw milk samples was $11.6 \%$ and 9.7\% according to MRT and ELISA, respectively. These findings are harmonious with published similar studies from Pakistan (14), Iraq $(10,13,15)$, and India (16). On the other hand, higher rates of anti-Brucella antibodies were documented in studies in Libya 21\% (17), India 27\% (18), Egypt 36.4\%-56.2\% (19), and Iran 45\% (20). Such variations might be attributed to various factors including the extent of encounters with wildlife (natural reservoirs), seasonality, level of available veterinary care, and testing methodology $(10,13)$.

The incidence of Brucella among raw milk of sheep and goat at Erbil seems comparable to different populations. The overall isolation percentage of Brucella spp. in this work $7.1 \%$ is comparable to previous studies in Erbil ewes and nanny goats populations (10), and also in cow and buffalo populations (2). A Nigerian study also detected a similar prevalence in livestock by the bacteriological approach (21). Besides, different rates of Brucella contaminating sheep and goats' raw milk were found in Iran ranged from $1.2 \%$ to $45.5 \%(20,22)$. In addition to seasonal and epidemiological variations in different regions, isolation of Brucella is also influenced by the bacteriological protocol. Indeed, isolation from the milk samples may be enhanced if more than one of the culture medium is used (13). The observation that $\mathrm{Br}$. melitensis is the predominant species is consistent with previous literature $(10,13)$. Indeed, this observation may explain the difference in prevalence between goats and sheep populations in the present work.

MRT is an inexpensive serological test that was found to be $95.9 \%$ specific to rule out infection $(91.2-98.5 \%, 95 \%$ CI). This finding is in good agreement with previous studies that found the sensitivity and specificity of MRT to be $85 \%$ and $95 \%$ in sheep and goat populations, respectively (12). However, an Egyptian large study found a complete sensitivity $100 \%$ when testing milk samples of cow and buffalo, whereas it dropped to $93 \%$ when milk samples from goats and sheep were tested (19). It should be noted that both of serological tests and culture method have a lower sensitivity in comparison to recent molecular diagnostic procedures, but this drawback is recompensed by the fact that the MRT is cheap and easy to perform (19). Meanwhile, ELISA and PCR approaches are expensive and unusual in several developing countries $(23,24)$.

The seasonality of brucellosis is expected to be linked to human activities and climatic variability. Indeed, short sunshine duration and lower temperatures during winter and spring were found to be strongly related to temporal peaks in 
the occurrence of brucellosis. The seasonality of brucellosis in sheep and goats was also reported to be attributed to the seasonal birthing (23). Moreover, human cases were found to be directly related to the parturition of small ruminants. On the contrary, other studies from northern hemisphere countries had reported an increase in the incidence of brucellosis during summer and spring (25).

According to (25), the mass vaccination is vital for the control and eradication of ovine and caprine brucellosis, also there are other complementary measures that may need attention include restriction and control of trade, improved farm hygiene, limit the movement of animals, testing of animals and isolation the infected animals. We must educate the farmers that the cornerstone of zoonotic infectious disease epidemiology is the One Health conception. One Health is not new, but it has become more important in recent years. It is a collaborative, multisectoral, and transdisciplinary program, working at the global national, and local levels, with the goal of attaining optimal health outcomes diagnosing the correlation between individuals, animals, plants, and their mutual environment. The eradication or control of the brucellosis among farming and wildlife animals is essential for the control of the disease in human populations.

\section{Conclusions}

Brucellosis still one of the most predominant zoonotic diseases that can seriously affect humans' health and food producing animals. The occurrence of brucellosis in ovine and caprine flocks was moderate in Erbil governorate. This percentage in sheep and goat milk is consider risky for public health. Consumers are highly recommended to properly heat raw milk before consumption in order to destroy this milk borne pathogen. Simple screening by MRT can be used for fast routine monitoring of lactating sheep and goats. The epidemiology and seasonal differences in brucellosis among raw milk of sheep and goats in Erbil is not completely clear. A whole-year wide study is recommended to provide more epidemiological data regarding the incidence, seasonality, and other associated factors. Advancement of health attentiveness through the media (audio, visual media, and newspapers) is advised to highlight the procedure of transmission and prevention of animal-to-human infections.

\section{Conflict of interest}

The authors have no conflict of interest.

\section{Acknowledgements}

Author thank Knowledge University for supporting.

\section{References}

1. Wareth G, El-Diasty M, Melzer F, Schmoock G, Moustafa SA, ElBeskawy M, Khater DF, Hamdy MER, Zaki HM, Ferreira AC,
Ekateriniadou LV, Boukouvala E, Abdel-Glil MY, Menshawy AMS, Sancho MP, Sakhria S, Pletz MW, Neubauer H. MLVA-16 Genotyping of Brucella abortus and Brucella melitensis Isolates from Different Animal Species in Egypt: Geographical Relatedness and the $\begin{array}{lll}\text { Mediterranean Lineage. Pathog. 2020;9:498. DOI: } & \end{array}$ 10.3390/pathogens 9060498

2. Al-Mashhadany DA. The significance of milk ring test for identifying Brucella antibodies in cows and buffaloes' raw milk at Erbil governorate, Iraq. Iraqi J Vet Sci. 2019;33:395-400. DOI: 10.33899/ijvs.2019.163085

3. Akya A, Bozorgomid A, Ghadiri K, Ahmadi M, Elahi A, Mozafari H. Usefulness of Blood Parameters for Preliminary Diagnosis of Brucellosis. J Blood Med. 2020;11:107-13. DOI: 10.2147/JBM.S245513

4. Li Z, Wang XM, Zhu X, Wang M, Cheng H, Li D, Liu ZG. Molecular characteristics of Brucella isolates collected from humans in Hainan Province, China. Front Microbiol. 2020;11:452. DOI: $10.3389 /$ fmicb.2020.00452

5. Scholz HC, Banai M, Cloeckaert A, Kämpfer P, Whatmore AM. Brucella. In: Garrity GM, Bell JA, Lilburn T, Whitman WB, editors. Bergey's Manual of Systematics of Archaea and Bacteria. New Jersey: John Wiley \& Sons; 2018. 1-38 p. DOI: 10.1002/9781118960608.gbm00807.pub2

6. Tiller RV, Gee JE, Frace MA, Taylor TK, Setubal JC, Hoffmaster AR, De BK. Characterization of novel Brucella strains originating from wild native rodent species in North Queensland, Australia. Appl Environ Microbiol. 2010;76:5837-5845. DOI: 10.1128/AEM.00620-10

7. Hassan H, Salami A, Nehme N, Al Hakeem R, El Hage J, Awada R. Prevalence and prevention of brucellosis in cattle in Lebanon. Vet World. 2020;13:364-371. DOI: 10.14202/vetworld.2020.364-371

8. Bodenham RF, Lukambagire AS, Ashford RT, Buza JJ, CashGoldwasser S, Crump JA, Kazwala RR, Maro VP, McGiven J, Mkenda N, Mmbaga BT. Prevalence and speciation of brucellosis in febrile patients from a pastoralist community of Tanzania. Sci Rep. 2020;10:111. DOI: $10.1038 / \mathrm{s} 41598-020-62849-4$

9. Al-mashhadany DA. The Role of Milk Ring Test in Monitoring Brucellosis among Cow Milk in Erbil Governorate, Iraq. Int J Biol Pharm Allied Sci. 2018;5:802-19. DOI: 10.31032/IJBPAS/2018/7.5.4439

10. Almashhadany DA. The Utility of MRT to Screen Brucellosis among Ewe and Nanny Goats Milk in Erbil Governorate, Iraqi Int J Biol Pharm Allied Sci. 2018;7:1786-1802. DOI: 10.31032/IJBPAS/2018/7.9.4551

11. Almashhadany DA, Osman AA. Isolation, Serotyping, and Antibiogram of Salmonella Isolates from Raw Milk Sold at Retail Vending in Erbil City, Iraq. Bull Univ Agric Sci Vet Med Cluj-Napoca Anim Sci Biotechnol. 2019;76:116-122. DOI: 10.15835/buasvmenasb.0020.19

12. Hadad JJ, Almashhadany DA, Alaboudi AR. Isolation of Brucella Strains from Dairy Products in Ninevah Province, Iraq. Iraqi J Vet Sci. 1997;10:39-44.

13. Al-Farwachi, MI, Al- Badrani, BA, Al-Nima, TM. Detection of Brucella antigen in the aborted ovine fetal stomach contents using a modified ELISA test. Iraqi $\mathrm{J}$ Vet Sci. 2010;24:1-4. DOI: 10.33899/ijvs.2010.5577

14. Hussain MA, Rind R, Adil M, Khan M, Farmanullah, Sikandar A, Waheed U, Salim M. Seroprevalence of Brucellosis in sheep and humans in District Kohat, Pakistan. Adv Anim Vet Sci. 2014;2:516523. DOI: $10.14737 /$ journal.aavs/2014/2.9.516.523

15. AL-Shemmari IG. Comparative study between conventional and molecular tests to detect the incidence of brucellosis in cattle and buffaloes in Babylon and Karbala provinces. Sci J Med Res. 2018;2:713. DOI: $10.37623 /$ SJMR.2018.2502

16. Mohamand N, Gunaseelan L, Sukumar B, Porteen K. Milk Ring Test for spot identification of Brucella abortus infection in single cow herds. J Adv Vet Anim Res. 2014;1:70-72. DOI: 10.5455/javar.2014.a8

17. Al-Griw HH, Kraim ES, Farhat ME, Perrett LL, Whatmore AM. Evidence of ongoing brucellosis in livestock animals in North West Libya. J Epidemiol Glob Health. 2017;7:285-8. DOI: 10.1016/j.jegh.2017.09.001 
18. Dubey P, Patel KB, Patel BK, Chauhan HC, Chandel BS, Patel SS. Molecular detection of Brucella organism from milk and milk products. Int J Curr Microbiol Appl Sci. 2017;6:1087-91. DOI: 10.20546/ijcmas.2017.604.135

19. Wareth G, Melzer F, Elschner MC, Neubauer H, Roesler U. Detection of Brucella melitensis in bovine milk and milk products from apparently healthy animals in Egypt by real-time PCR. J Infect Dev Ctries. 2014;8:1339-1343. DOI: $10.3855 /$ jidc. 4847

20. Moslemi E, Soltandalal MM, Beheshtizadeh MR, Taghavi A, Kheiri Manjili H, Mahmoudi Lamouki R. Detection of Brucella spp. in Dairy Products by Real-Time PCR. Arch Clin Infect Dis. 2018;13:e12673. DOI: 10.5812/archcid.12673

21. Ocholi RA, Kwaga JKP, Ajogi I, Bale JOO. Phenotypic characterization of Brucella strains isolated from livestock in Nigeria. Vet Microbiol. 2004;103:47-53. DOI: 10.1016/j.vetmic.2004.06.012

22. Shirazi Z, Khalili M, Sadeghi B, Sharifi H, Ashrafganjooyi S. Detection of Brucella spp. in the Sheep and Goats Milks from Southeastern Iran Using Culture and PCR. J Med Microbiol Infect Dis. 2017;5:40-2. DOI: 10.29252/JoMMID.5.3.4.40

23. Soulieman N, Al-Mariri A, Al-Atrash F. Detection of Shigella in raw bovine milk by polymerase chain reaction. Iraqi J Vet Sci. 2020;34:916. DOI: $10.33899 /$ ijvs.2019.125758.1146

24. Ahmed IM. Detection of CTX-M gene in extended spectrum $\beta$ lactamases producing Enterobacteriaceae isolated from bovine milk. $\begin{array}{lllll}\text { Iraqi J } & \text { Vet }\end{array}$ 10.33899/ijvs.2020.126909.1412

25. Dadar M ,Tiwari R, Sharun K, Dhama K. Importance of brucellosis control programs of livestock on the improvement of one health. Vet Q. 2021;41:137-151. DOI: $10.1080 / 01652176.2021 .1894501$

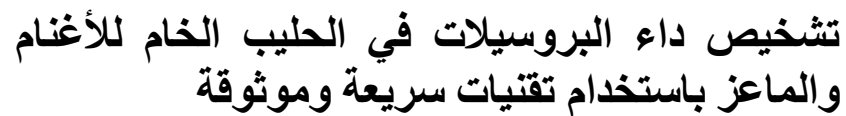

$$
\text { ضاري عليوي المشهاني }
$$

قسم علوم المختبرات الطبية، كلية العلوم، جامعة نولج، أربيل، العراق

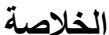

أجريت هذه الدر استة لمعرفة مدى انتشار داء البروسيلات بين الحليب

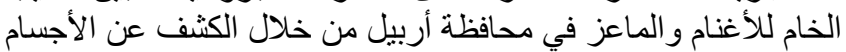

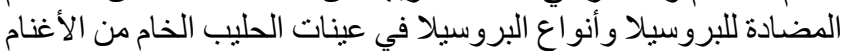

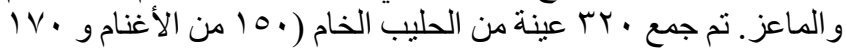

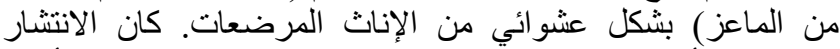

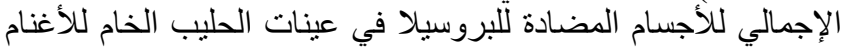

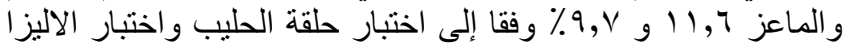

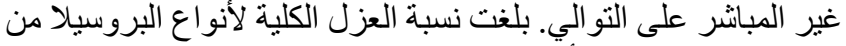

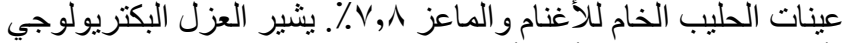

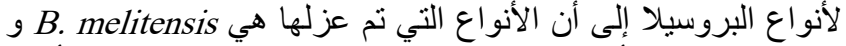
B. abortus

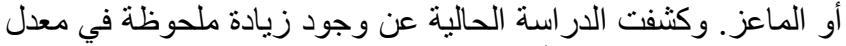

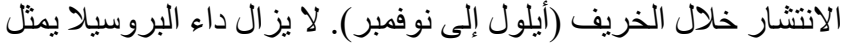

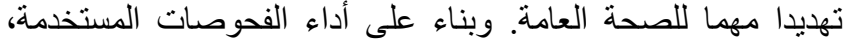

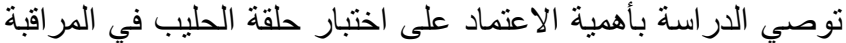

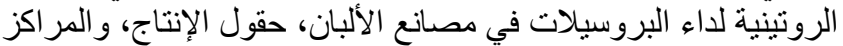

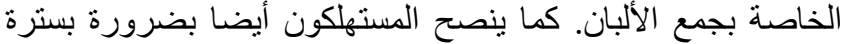

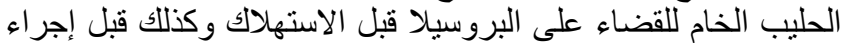

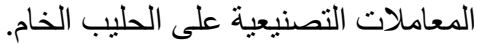

